http://dx.doi.org/10.5007/2175-7968.2014v1n33p169

\title{
O PROCESSO TRADUTÓRIO NA CAMPANHA "ROSIE THE RIVETER": A QUESTÃO DA VISIBILIDADE DO SUJEITO COM DEFICIÊNCIA
}

\author{
Érica Danielle Silva* \\ Universidade Estadual de Maringá \\ Ismara Eliane Vidal de Souza Tasso** \\ Universidade Estadual de Maringá
}

\begin{abstract}
Resumo: Este artigo tem como objetivo geral trazer à tona algumas discussões acerca da noção de processo tradutório, reconhecendo a existência de mecanismos de produção de sentidos materializados em práticas tradutórias no entrecruzamento da língua e do discurso. Assumindo uma visão discursiva, partimos da hipótese de que a tradução é produtora de significados que podem ser construídos por regimes políticos, sociais, econômicos e institucionais de produção de verdades em um determinado momento histórico. Objetivamos, de modo específico, refletir sobre o processo tradutório de um texto selecionado a partir de um corpus composto por três materialidades, considerados neste estudo como traduções (intra)interlinguais do cartaz criado por J. Howard Miller para uma campanha di-
\end{abstract}

\footnotetext{
* Mestre em Estudos Linguísticos, na linha de pesquisa "Estudos do Texto e do Discurso" (2010) e graduada em Letras - habilitação Português/Inglês (2007) pela UEM. Doutoranda em Letras na Universidade Estadual de Maringá - UEM. Maringá, Paraná, Brasil. E-mail: erica_dsilv@yahoo.com.br

** Professora do Departamento de Língua Portuguesa e do Programa de Pós-graduação em Letras na Universidade Estadual de Maringá. Editora Associada da Revista Acta Scientiarum. Language and Culture. Líder do GEDUEM/CNPq Grupo de Estudos em Análise do Discurso da Universidade Estadual de Maringá. Maringá, Paraná, Brasil. E-mail: tassojs@terra.com.br
} 
vulgada durante a segunda Guerra Mundial, nos Estados Unidos, que tem como personagem principal Rosie the Riveter. Problematizamos, então, as condições de produção de uma das traduções destacadas, cuja personagem Rosie the Riveter é representada por uma jovem com Síndrome de Down, tomando esse objeto como um lugar em que se pode desvendar as perturbações da continuidade histórica que se cruzam em sua constituição. Palavras-chave: Sujeito com deficiência. Processo tradutório. Rosie the Riveter. Condições de produção. Língua, discurso e história.

\title{
THE TRADUCTION PROCESS IN THE CAMPAIGN "ROSIE THE RIVETER": THE VISIBILITY OF THE PERSON WITH DISABILITIES
}

\begin{abstract}
This article aims at bringing up some discussions about the concept of the translation process, recognizing the existence of mechanisms of production of meanings materialized in practices of translation in the intersection of language and discourse. Assuming a discursive view, we depart from the hypothesis that the translation is a producer of meanings that can be constructed by political regimes, social, economic and institutional production of truths in a particular historical moment. We aim at reflecting on the translation process of a text selected from a corpus composed of three materialities, considered here as (intra)interlingual translations of a poster created by Howard Miller for a campaign released during the second World War, in the United States, which has as the main character Rosie the Riveter. Then, we problematize the conditions of production of one of the selected translation, whose main character, Rosie the Riveter, is represented by a young man with Down syndrome, taking this object as a place where it can unravel the disruption of historical continuity that intersect at its constitution.
\end{abstract}

Keywords: People with disabilities. Translation process. Rosie the Riveter. Conditions of productions. Language, discourse and history. 


\section{Por uma concepção discursiva da tradução}

As tendências atuais de democratização da tecnologia têm problematizado os mecanismos subjacentes ao processo da tradução, o que configura uma perspectiva contestadora da tradução, ideia compartilhada por autores como Francis H. Aubert, Rosemary Arrojo, Lawrence Venutti e Theo Hermans. Ao retratar tal realidade, Batalha (2007) explica que apesar de não ser possível organizar um "manual de tradução", haja vista que não há consenso entre as diferentes soluções metodológicas propostas pelos estudiosos, é possível refletir criticamente sobre os limites, implicações e operações interpretativas e linguísticas envolvidas nesse processo.

Para este trabalho, situamo-nos no imbricamento de questões da língua, do discurso e da história, que podem funcionar como dispositivos analíticos que pretendem viabilizar o reconhecimento de mecanismos de produção de sentidos materializados em práticas tradutórias. Logo, ancoramo-nos na concepção de tradução sob a ótica da Análise de Discurso que, conforme orienta Mittman (2003, p.16), considera as condições históricas de constituição do sentido e do sujeito. Olhar a tradução por esse viés teórico-metodológico implica, assim, ter um novo objeto de reflexão, ou seja, passar da noção de tradução para a de processo tradutório.

Mittman (2003, p.103) explica que o processo tradutório não se atém no ato individual do tradutor, mas é um processo "de relação de sentidos e de produção de discursos, que surge a partir de condições sócio-históricas de produção". Consequentemente, essa concepção nos leva a reconhecer o autor e o tradutor como uma "função": a função-autor que controla e limita o significado do texto (FOUCAULT, 2007a) e a função-tradutor, que "é responsável pela organização das vozes presentes no processo tradutório, bem como pelo direcionamento de uma interpretação, criando a ilusão da homogeneidade e da transparência” (MITTMAN, 2003, p. 136).

Arrojo (1986, p. 38) corrobora com essa discussão, na medida em que considera que "todo leitor ou tradutor não poderá evitar que 
seu contato com os textos (e com a própria realidade) seja mediado por suas circunstâncias, suas concepções, seu contexto histórico e social". Em função disso, devemos problematizar a concepção de verdade, que na perspectiva discursiva, sobretudo nos estudos foucaultianos, é regida pelo princípio de que é sempre uma construção entorno no papel político-econômico que ela desempenha, produzindo efeitos reguladores de poder (FOUCAULT, 2007c). Temos, assim, regimes políticos, econômicos e institucionais de produção da verdade que constituem nossa história.

É graças a essas produções de verdades que podemos problematizar a questão da fidelidade da tradução ao texto original. Arrojo (1986, p. 44, grifos da autora) argumenta que a "[...] tradução de qualquer texto, poético ou não, será fiel não ao texto 'original', mas àquilo que consideramos ser o texto original, àquilo que consideramos constituí-lo, ou seja, à nossa interpretação do texto de partida, que será, como já sugerimos, sempre produto daquilo que somos, sentimos e pensamos". Assim, conforme a autora, um tradutor, em sua comunidade cultural em uma determinada época, nunca poderia recuperar a totalidade do "original", uma vez que revela em seu texto uma leitura, uma interpretação do original que será "sempre, apenas lido e interpretado, e nunca totalmente decifrado ou controlado" (ARROJO, 1986, p. 22, grifos da autora).

A tradução, assim, deixa de ser uma atividade protecionista dos significados do texto original e assume uma condição de produtora de significados (ARROJO, 1986, p. 24), uma vez que o universo do autor do texto original será sempre, na tradução, uma visão daquilo que pode ter sido. Concepção essa que nos leva a considerar que a tradução e, consequentemente a língua, não é composta exclusivamente de palavras, mas contém uma visão de mundo própria que efetua recortes sobre o real.

Para o objetivo aqui proposto, consideraremos como texto "original", ou "texto de partida" o cartaz produzido por Howard Miller, nos Estados Unidos, durante a segunda Guerra Mundial, que ficou conhecido pelo título de "We can do it!", ou "Rosie the Rive- 
ter" ${ }^{1}$, produzido sob condições políticas e econômicas específicas. Entre 1939 e 1945 algumas empresas, ligadas à produção de equipamentos para a guerra, tiveram surpreendente expansão. Apesar do crescimento de postos de trabalho, não havia mão-de-obra suficiente, porque os americanos lutavam na Grande Guerra. Assim, para suprir a falta de operários, em 1942, o governo estadunidense empreendeu campanhas com objetivo de recrutar mulheres na força de trabalho em indústrias, no serviço civil e até nas forças armadas. Ocasião em que Rosie the Riveter tornou-se um ícone cultural dos Estados Unidos, por figurar como personagem principal no cartaz criado por J. Howard Miller, no qual retratava uma mulher forte, competente, como símbolo da mulher patriótica que não precisava sacrificar sua feminilidade para cumprir seu papel. Essa imagem, associada ao enunciado "We can do it", foi essencial para propagar a ideia de igualdade em relação aos homens, que também estariam cumprindo seu dever de patriota, na guerra.

A partir desse texto de partida, selecionamos dois textos que retomam enunciado em condições de produção outras. A primeira delas (Figura 1) faz parte de uma campanha lançada em San Francisco - Califórnia/EUA, em Outubro de 2011, que visava sensibilizar e criar oportunidades de emprego para pessoas com deficiência intelectual. The Arc. of San Francisco ${ }^{2}$, uma organização sem fins lucrativos divulgou a campanha e ofereceu serviços de advocacia para adultos com algum tipo de deficiência intelectual, paralisia cerebral, autismo ou Síndrome de Down e a seus familiares que viviam em San Francisco e em San Mateo. Dessa campanha, nasce o slogan "Ready, willing and able to work", cujos fins era o de agregar parcerias empresariais para dar fomento à integração de sujeitos com deficiência em sua equipe de funcionários, o que forneceria, consequentemente, suportes de vida independente e capacitação para formação profissional e expressão criativa desses sujeitos. Razão desse slogan produzir os sentidos como "Prontos, dispostos e capazes para o trabalho". 


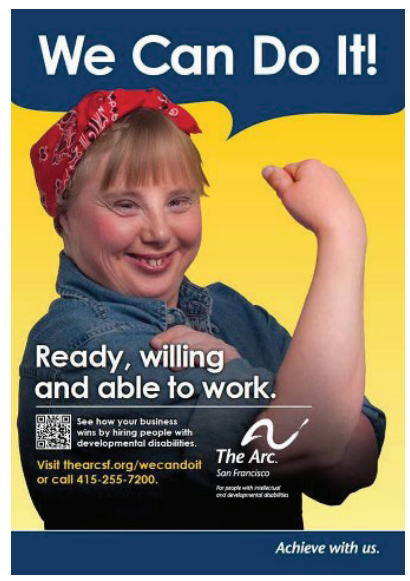

Figura 1: Campanha lançada nos EUA, em 2011, com o objetivo de criar oportunidades de emprego para pessoas com deficiência intelectual.

A segunda materialidade (Figura 2) corresponde a uma homenagem criada pela agência de comunicação Creato para o dia Internacional da Mulher, 08 de março, em 2012. Segundo a descrição da equipe de criadores, é uma versão "moderninha e cheia de estilo" da Rosie the Riveter. Percebe-se que ao traduzir o enunciado original "We can do it" para a língua portuguesa, a função autor marca visualmente e linguisticamente - com pontos de exclamação e reticências - três momentos na declaração da personagem, acrescentando uma expressão importante: "e de salto alto!". Importa destacar também, ainda nessa materialidade, a versão "moderna" da Rosie the Riveter, apresenta-se com um traje que enfatiza o braço tatuado, estilo corporal do jovem da contemporaneidade, assim como se destaca a ênfase à palavra "sim", efeito de sentido (globalizado) para "Yes!". . Ambos sob o efeito do jogo de luz no segundo plano, inexistente na composição "original”. 


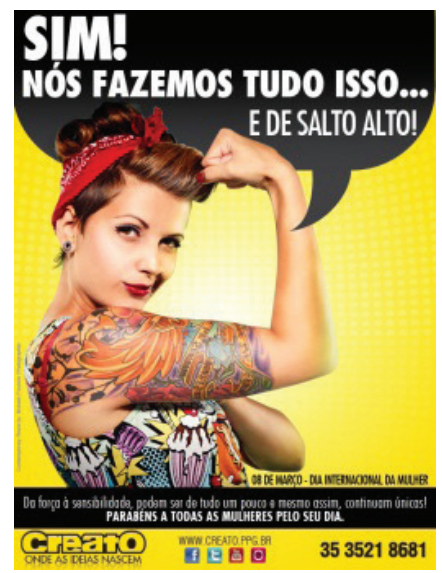

Figura 2: «Contemporary Rosie », de Michael Fournier Photographer. ${ }^{3}$

Conforme o que levantamos no início deste texto, poderíamos, então, considerar uma "traição ao original" o resultado da composição desenvolvido pela agência de comunicação Creato (materialidade 2)? Se a perspectiva do olhar a tradução é o discursivo, não. Considerando o conjunto de textos reunidos, é possível visualizar um acesso a outras leituras de mundo, o que segundo Batalha pode enriquecer

a rede de intertextualidade, de interdisciplinaridade e de interculturalidade entre os povos, ela também suscita a reflexão sobre o estatuto do texto traduzido. Aí reside a visada dupla de todo ato tradutório: a necessidade de conciliar a fidelidade ao original com o desejo de adaptação ao contexto da nova língua. Trocando em miúdos, traduzir é recontextualizar um pensamento original; sabemos, entretanto, que esse processo não está isento de ideologias e motivações diversas que vão além das simples questões de ordem linguística (BATALHA, 2007, p. 74). 
Nessa linha de raciocínio e pautados na rede teórica foucaultiana, verificamos as relações entre os elementos dessa série e o modo como cada materialidade e elemento que a constitui significam, constroem e produzem sentido. Esse método de estudo permite, então, a compreensão dos sentidos a partir da análise dessa rede interdiscursiva formada, na relação que um enunciado mantém com os demais. Ao levar em conta as materialidades selecionadas, vemos a regularidade de volta ao passado, uma vez que os enunciados mais recentes retomam o texto de partida. Há, no entanto, uma nova "roupagem", ou seja, um outro acontecimento discursivo que ressignifica o enunciado. Em outras palavras, cada tradução desconstrói o texto de partida para então reconstruir o discurso, que nos casos selecionados referem-se ao movimento inclusivo das pessoas com deficiência e ao papel da mulher na sociedade contemporânea.

Um fator intrigante nas traduções/versões em relação ao texto de partida diz respeito à constituição imagética que efetua recortes sobre o real nas condições específicas de produção de cada materialidade. Considerando, então, que uma língua não é composta exclusivamente por palavras (OUSTNOFF, 2011), podemos nos aproximar da noção de tradução intersemiótica, desenvolvida por Roman Jakobson (2010, p. 79). Em linhas gerais, a questão que se coloca é a operação sobre signos, que abrange um domínio mais amplo do que a língua. Jakobson, inspirando-se nos escritos de Charles Sanders Peirce, distingue três tipos de tradução: (a) a tradução intralingual ou reformulação - reescritura que se mantém na mesma língua -, (b) a tradução interlingual ou tradução propriamente dita - de um idioma a outro - e (c) a tradução intersemiótica - de um meio marcado por signos verbais a outro com signos não verbais. Nota-se que, apesar de didática, tal distinção se mescla, a medida que tratamos dos três grupos no conjunto de materialidades selecionado.

Apesar de sabedores das problematizações levantadas acerca dessa classificação, sobretudo aquelas elaboradas por Derrida (2002) e Hermans (1996), não objetivamos tratar esses aspectos 
nos limites deste texto. Gostaríamos, apenas, neste momento, que o leitor visualizasse os efeitos de sentido construídos na tradução de uma materialidade para composições outras em uma mesma língua que o texto de partida ou em uma língua diferente e o peso da interpretação de signos visuais não linguísticos na leitura da materialidade. Tocamos, desse modo, na questão da traduzibilidade do enunciado, cujo percurso iniciou-se na interpretação do texto de partida para transformar/traduzir em uma materialidade outra. Isso significa dizer que o efeito de sentido basilar de capacidade, materializado no texto de partida, foi atribuído para outros sujeitos, em outras condições de produção, o que implica a reflexão das diferenças e não da igualdade (Derrida, 2002). Nessa multiplicidade de variantes, o texto de partida sobrevive em sua essência, o que contribui para sua continuidade, mas se modifica em consonância com a renovação e transformação da língua e das motivações sociais que introduzem novos elementos. Aproximamo-nos, então, da tarefa do tradutor, que, conforme a concepção de Derrida (2002) refere-se ao engajamento deste no intervalo entre autor e leitor, texto e contexto. Isso significa dizer que o tradutor transforma um texto em outro, contribuindo para a continuidade da obra.

0A partir do que foi dito, filiando-nos a Foucault (2007b), a fim de compreender as condições de existência desses enunciados, interrogamos "que singular existência é esta que vem à tona no que se diz e em nenhuma outra parte?" Partimos da hipótese de que a tradução é produtora de significados que podem ser construídos por regimes políticos, sociais, econômicos e institucionais de produção de verdades em um determinado momento histórico. Isso equivale a dizer que as materialidades selecionadas só fazem sentido em condições de produção específicas: somente com o movimento em prol da inclusão de pessoas com deficiência ou a liberação feminina quanto ao seu corpo, é possível atribuir efeitos de verdade a esses enunciados.

Sob tal conjuntura e de modo específico, o processo tradutório da primeira "tradução" correspondente à campanha lançada 
em San Francisco - Califórnia/EUA, em Outubro de 2011, não poderiam ser problematizadas abstendo-se de suas condições de produção, mas de outro modo, com a tomada desse objeto como um lugar em que se podem desvendar as perturbações da continuidade histórica que se cruzam em sua constituição.

\section{Rose the Riveter com síndrome de down: a tradução pro- duzindo (novos) sentidos}

Nesta parte do estudo abordamos algumas considerações acerca da materialidade apresentada na figura 1 , em que a personagem Rosie the Riveter é representada por uma jovem com Síndrome de Down. Tomamos a posição de que a campanha é uma tradução intersemiótica da campanha divulgada durante a segunda Grande Guerra, aqui texto de partida. Notamos que o teor histórico se sobrepõe, haja vista que a versão atual não se distancia da ideia construída no texto de partida. Assim, é preciso pensar a significação do enunciado atual como um produto da história: que elementos históricos/econômicos/sociais devem ser de conhecimento do leitor para construir uma interpretação coerente do texto, ou seja, para atribuir-lhe sentido?

Da mesma forma, para que possamos interpretar a materialidade selecionada, fez-se necessária a sua localização no tempo e no espaço. Isso significa considerar as condições de produção da propaganda, que destaca não apenas uma mulher, mas uma mulher com deficiência. Razão de nos reportamos à historicidade do corpo deficiente, ao movimento empreendido a partir do século XX, sobretudo depois da Primeira Guerra Mundial (1914-1918), voltados para a assistência das pessoas com deficiência que passaram a contemplar a reabilitação desses sujeitos. Silva $(1987$, p. 310) ressalta que os estudiosos do movimento de reabilitação provocaram, nesse período, "um intercâmbio de informações e de sugestões entre todos os que se interessavam pelo problema, estabelecendo uma 
espécie de organização internacional de caráter informal”. O período pós-guerra, além de causar mudança de sensibilidade diante do corpo monstruoso, estimulou programas de reabilitação, possibilitando serviços gratuitos para as pessoas que portavam deficiências devido à atividade militar, tal como na França, país que garantiu, gratuitamente, para a pessoa "incapacitada" fisicamente, a inscrição em uma escola profissionalizante para que ela pudesse ser recolocada no mercado de trabalho, além de cuidados médicos, aparelhos ortopédicos e cadeiras de rodas (SILVA, 1987).

A conscientização de programas mais amplos de incentivo à reabilitação física, que também se estendessem à deficiência mental e às deficiências sensoriais, ganhou força com o fim da Segunda Guerra Mundial (1939-1945). Sensibilizadas pela causa da deficiência, organizações internacionais, comandadas pela Organização das Nações Unidas, entre elas o Fundo de Emergência das Nações Unidas para as Crianças (UNICEF), a Organização Internacional do Trabalho (OIT), a Organização Mundial de Saúde (OMS), a Organização das Nações Unidas para Refugiados e a Organização das Nações Unidas para Educação, Ciência e Cultura (UNESCO) desenvolveram um contínuo e silencioso trabalho a fim de que a reabilitação chegasse à maioria dos países do mundo.

Dentre as medidas de alcance universal, aprovadas pela Assembleia Geral da ONU, destacam-se as Declarações dos Direitos das Pessoas com Retardo Mental, em 1971, e a dos Direitos das Pessoas Deficientes ${ }^{4}$, em 1975. Ambas tiveram por finalidade estabelecer formas de conduta para o tratamento equânime da questão, tendo em vista a assistência à deficiência física preponderar sobre as demais. A partir dessa época, oficializa-se o direito ao exercício pleno de cidadania aos sujeitos com deficiência: saúde, educação, moradia e capacitação profissional, condição para torná-lo útil e produtivo à sociedade, um corpo dócil.

Inúmeras medidas, de iniciativa estatal e de organizações não governamentais, voltadas à conscientização sobre a deficiência foram tomadas por organizações públicas e particulares, tal como 
ocorreu com a promulgação do Ano Internacional da Pessoa Deficiente (Resolução 31/123, em 1976), pela ONU, em 1981. Com o tema "Participação plena e igualdade" e com o objetivo de "dar condições para a implementação das resoluções anteriores, pela conscientização do mundo todo quanto à problemática das pessoas portadoras de deficiências" (SILVA, 1987, p. 329), o projeto deu visibilidade à extensão do problema instaurado por milênios de discriminação e de desvalorização do deficiente (SILVA, 1987).

Como ponto culminante desse processo de conscientização, o período de 1983 a 1992 foi declarado a "Década das Pessoas Portadoras de Deficiência”. Período em que foi instituído um Programa de Ação Mundial (Disponível em < http://www.cedipod.org.br/ w6pam.htm > , Acessado em 10/08/2009), com o objetivo de promover medidas para a prevenção das incapacidades e a participação plena das pessoas com deficiência na vida social. Tal documento, de âmbito internacional, detalhava o tratamento a ser dado aos sujeitos pertencentes a esse grupo. Aclamava-se, na ocasião, que as pessoas com deficiência deveriam desempenhar suas obrigações como adultos, já que suas atitudes influenciavam na construção da imagem dessas pessoas na sociedade. Estimulou-se a criação de organizações compostas pelas próprias pessoas com deficiência, a fim de que expressassem opiniões acerca das prioridades e assim viessem a exercer influência sobre as instâncias governamentais responsáveis pelas decisões, bem como sobre todos os setores da sociedade. Para isso, segundo o programa, fazia-se necessário que todos os meios de informação pública cooperassem, apresentando essencialmente a importância da mudança de atitudes ao público, de modo a combater os estereótipos e os preconceitos tradicionais. A fim de efetivar essa última proposta, destaca-se a importância atribuída à representação das pessoas com deficiência, veiculadas no rádio, no cinema, na fotografia e na imprensa. Segundo o programa, um elemento fundamental nesse processo seria o de que as pessoas deficientes tivessem a oportunidade de apresentar elas próprias seus problemas, bem como sugerir formas de resolvê-los. 
Nota-se, a partir dessa mobilização, que as pessoas com deficiência foram chamadas a cumprir seu direito de participação na sociedade, e ao Estado coube efetivar ações concretas de acessibilidade e de igualdade, por meio de políticas públicas. Através de documentos oficiais, estimulou-se o investimento econômico e a sensibilização dos direitos adquiridos por esse grupo. Dessa for$\mathrm{ma}$, as iniciativas voltadas a proporcionar o bem-estar e o direito à cidadania das pessoas com deficiência compreendiam, além de eliminação de barreiras arquitetônicas, também as sociais relacionadas ao preconceito e à discriminação.

Com o término da Década da Pessoa Deficiente e devido aos problemas ainda existentes, a ONU manifesta o desejo de que as metas do Programa de Ação Mundial se estendessem para além da década estipulada. Propôs-se concluir com êxito, em 2010, uma sociedade "para todos", por intermédio de planos estratégicos de prevenção, reabilitação e equiparação de oportunidades. Além disso, destacou-se a preocupação linguística, solicitando-se a revisão de traduções dos termos "impedimento", "deficiência" e "incapacidade".

A partir dos apontamentos históricos/sociais até aqui e tomando o projeto foucaultiano como abordagem teórico-metodológica, parte-se do princípio de que a caracterização biológica da deficiência de uma pessoa está também condicionada a complexas relações entre os domínios do saber e do poder. Como explica Veiga-Neto (2007), uma analítica do sujeito, nessa perspectiva, não parte do próprio sujeito, mas dos saberes e das práticas discursivas e não discursivas que o envolvem. As práticas e os saberes, "uma vez descritos e problematizados poderão revelar quem é esse sujeito, como ele chegou a ser o que dizemos que ele é e como se engendrou historicamente tudo o que dizemos dele" (VEIGA-NETO, 2007, p.113).

Tendo em vista que esse sujeito é significado por práticas discursivas de campos de saberes diversos, é ele um efeito de complexas relações de poder estabelecidas no âmbito do corpo social. Por isso, os mecanismos de poder encontram-se associados à produção, 
à acumulação e à circulação de discursos e não apenas às formas jurídicas (FOUCAULT, 2007c). O sistema de direito, assim, não assegura a legitimidade a ser respeitada pelos indivíduos, mas é um procedimento de sujeição.

Assim, no domínio das deficiências, a deficiência insere-se em processos biológicos mais amplos, que não privilegiam apenas o corpo, mas também seus efeitos sobre a população, haja vista que a acessibilidade das pessoas com deficiência a espaços sociais diversificados - escola, mercado de trabalho, entre outros - promove o contato com o diferente. Dessa forma, cria-se a condição de possibilidade de a deficiência ser estabelecida no entrecruzamento dos mecanismos de disciplina e de regulamentação.

Nota-se que a alternância do domínio da deficiência entre a ordem do individual e a do social funciona como dispositivo político, logo, de governamentalidade. Nesse movimento, a norma é o elemento que potencializa o funcionamento dos mecanismos de disciplina e de regulamentação e é a partir dela que se distingue quem se identifica com ela. A operação de normalização consiste, pois,

em fazer essas diferentes distribuições de normalidade funcionarem umas em relação às outras e [em] fazer de sorte que as mais desfavoráveis sejam trazidas às que são mais favoráveis. Temos portanto aqui uma coisa que parte do normal e que se serve de certas distribuições consideradas, digamos assim, mais normais que as outras, mais favoráveis em todo caso que as outras. São essas distribuições que vão servir de norma. A norma está em jogo no interior das normalidades diferenciais. O normal é o que é primeiro, e a norma se deduz dele, ou é a partir desse estudo das normalidades que a norma se fixa e desempenha seu papel operatório. Logo, eu diria que não se trata mais de uma normação, mas sim, no sentido estrito, de uma normalização. (FOUCAULT, 2008, p. 82-83). 
Importa destacar que um dos operadores fundamentais para tais mudanças é a população (FOUCAULT, 2008). Razão de deixá-la circular, desde que os perigos dessa circulação fossem anulados. Assim, não mais a segurança do príncipe e de seu território estaria assegurada, mas a da população e, consequentemente, de quem a governa. Trata-se, de delimitar marcos aceitáveis, em vez de impor-lhes uma lei que diga não (FOUCAULT, 2008). Um dos principais elementos que movem essas estratégias de gerência da população é, segundo Foucault (2008), o desejo. É por meio dele que a população se torna penetrável pelas estratégias do poder. Esse desejo permite a produção de algo interessante e natural para a população, bem como a artificialidade dos meios criados para governá-la. Logo, ao contrário do soberano que dizia "não" aos desejos dos indivíduos, forma-se um pensamento econômicopolítico em que a problemática que se instaura para aqueles que governam é saber como dizer "sim" ao desejo da população.

Assim, nessas relações de poder, língua e imagem constituem instrumentos que articulam os saberes via discurso. Por essa razão, retomamos a imagem da campanha em prol do incentivo à contratação de pessoas com deficiência. Percebemos o "sim" que ressoa nas duas partes envolvidas: pelo sujeito deficiente que afirma sua capacidade de trabalhar e pela empresa que ao dizer "sim" e aceitar um sujeito deficiente em sua equipe pode obter vantagens. Nessa versão, a ideia de integração e humanização suscitada pelo saber científico manifesta-se no discurso sobre a "inclusão", termo polêmico e importante para o movimento discursivo em torno da pessoa com deficiência, em todos os campos sociais. A inclusão é entendida como fundamento do modelo social de deficiência que faz parte de um complexo conjunto de condições criadas pelo contexto social. Entende-se que a base do paradigma inclusivista consiste em uma proposta de construção de cidadania, o que significa um processo de mão-dupla: tanto a 
pessoa com deficiência como a sociedade precisam se modificar. (BARTALOTTI, 2006, p. 23-24).

A emergência do discurso inclusivo, nem sempre considerada, pode ser materializada não só pela língua, mas também pela imagem fixa ou pela efêmera, que surgem problematizando o presente e construindo novos saberes sobre o sujeito com deficiência. Consequentemente, carregam uma memória que afeta o modo como o sujeito constrói as significações em uma determinada situação discursiva e como sua identidade é construída. Nesse processo, a deficiência não é identificada apenas pelo corpo, mas esse sujeito passa a ser identificado por símbolos distribuídos em espaços específicos, que podem, assim, ser ressignificados. O corpo é, portanto, superfície que possibilita o exercício do poder, suporte e produtor de imagens, ou seja, materialidade discursiva que produz identidades. É através dele que também se exerce o dispositivo da inclusão.

Notamos que esses elementos utilizados para a construção de uma interpretação coerente do texto analisado contribuem para a constituição da significação da tradução - mesmo sendo intralingual -, como produto da história. Conforme destaca Arrojo (1986), o texto de partida dá lugar a uma outra interpretação, uma outra leitura em cada comunidade cultural e em cada época. "A tradução, como a leitura, deixa de ser, portanto, uma atividade que protege os significados 'originais' de um autor, e assume sua condição de produtora de significados”. (ARROJO, 1986, p. 24, grifo da autora).

\section{Tecendo efeitos de conclusão}

Em resumo, observamos que, nas materialidades levantadas, o processo tradutório que as constituem se configura a partir das noções de autoria, originalidade e (in)fidelidade, que estão, por sua vez, embasadas por questões da língua, do discurso e da história. Tomamos, nessa perspectiva, a figura da função-tradutor como 
aquele que organiza as vozes presentes no processo tradutório, direciona uma interpretação e resgata, reproduz ou reconfigura os sentidos do texto de partida.

Concluímos, assim, que as traduções tomadas como base da discussão sobre o processo tradutório, em especial aquela que traz uma jovem com Síndrome de Down, apontam para a configuração de um processo de caráter (re)criador e intermediador de fatores culturais importantes da sociedade contemporânea, que por sua vez depende da tradução para a circulação dos mais diversos tipos de informações. Se considerarmos o ano de criação da campanha texto de partida-, 1942, e o ano de criação da última materialidade selecionada para o corpus, a homenagem ao dia da mulher de 2012, notamos a passagem de 70 anos de mudanças sociais, políticas e econômicas no Brasil e no mundo. Logo, o texto de partida é também transformado, reescrito, repensado e reconstruído no tempo e no espaço, historicamente falando, sobrevivendo, portanto, no entrecruzamento da língua e do discurso.

\section{Notas}

1. MILLER, Howard. We can do it! [Rosie the Riveter]. Produzido por Westinghouse for the War Production Co-Ordinating Committee NARA Still Picture Brach. 1942. Série War Production Board. NAIL Control Number: NWDNS179-WP-1563. Disponível em: < http://www.archives.gov/> Acesso em 06/02/2012.

2. Disponível em: < http://thearcsf.org/> Acesso em 06/03/2012.

3. Disponível em < http://blog.creato.ppg.br/2012/08-de-marco-dia-internacional-da-mulher/ > . Acesso em 10/03/2012. 
4. Ambos dão expressão concreta aos princípios contidos na Declaração Universal dos Direitos Humanos, adaptada e promulgada em 1948. Podem ser lidas na íntegra no site http://www.faders.rs.gov.br/portal/index.php?id=legislacao\&cat $=6$ .Acesso em 12 mar. 2010.

\section{Referências}

ARROJO, Rosemary. Oficina de tradução - a teoria na prática. São Paulo: Ática, 1986.

BARTALOTTI, Celina Camargo. Inclusão social das pessoas com deficiência: utopia ou realidade?. São Paulo: Paulus, 2006. (Questões Fundamentais da Saúde, $11)$.

BATALHA, Maria Cristina. Tradução. Petrópolis, RJ: Vozes, 2007.

DERRIDA, J. Torres de Babel. Tradução de Junia Barreto. Belo Horizonte: UFMG, 2002.

FOUCAULT, Michel. A ordem do discurso. 15. ed. São Paulo: Edições Loyola, 2007a.

. A arqueologia do saber. Tradução de Luiz Felipe Baeta Neves. 7.ed. Rio de Janeiro: Forense Universitária, 2007b.

. Microfísica do poder. Organização e Tradução de Roberto Machado. 24. ed. Rio de Janeiro: Edições Graal, 2007c.

- Segurança, território, população: curso dado no Collège de France (1977-1978). Edição estabelecida por Michel Senellart, sob a direção de François 
Ewald e Alessando Fontana. Tradução Eduardo Brendão. Revisão da tradução Claudia Berliner. São Paulo: Martins Fontes, 2008. (Coleção Tópicos).

HERMANS, T. Translation's other. Inaugural Lecture, London: UCL, 1996.

JAKOBSON, Roman. Linguística e comunicação. Tradução de Izidoro Blikstein e José Paulo Paes. 22. ed. São Paulo: Cultrix, 2010.

MITTMANN, Solange. Notas do tradutor e processo tradutório: análise sob o ponto de vista discursivo. Porto Alegre: Ed.UFRGS, 2003.

OUSTNOFF, Michaël. Tradução: história, teorias e métodos. Tradução: Marcos Marcionilo. São Paulo: Parábola Editorial, 2011.

SILVA, Otto Marques da. A epopéia ignorada: a pessoa deficiente na História do mundo de ontem e hoje. São Paulo: Cedas, 1987.

VEIGA-NETO, Alfredo. Foucault\& a Educação. 2.ed. Belo Horizonte: Autêntica, 2007

Recebido: 15/01/2014

Aceito: 29/04/2014 